\title{
Editorial
}

\section{Novel Approaches and Technologies for Heritage Buildings Conservation: Editorial}

\author{
Massimo Coli ${ }^{1, *(D)}$ and Yoshi Iwasaki ${ }^{2}$ \\ 1 Department of Earth Sciences, Florence University, 50121 Firenze, Italy \\ 2 Geo Research Institute, 2-1-2 Otemae, Chuo-Ku, Kokumin-Kaikan, 6th Fl, Osaka 540-0008, Japan; \\ yoshi-iw@geor.or.jp \\ * Correspondence: coli@unifi.it; Tel.: +39-3291213813
}

check for

updates

Citation: Coli, M.; Iwasaki, Y. Novel Approaches and Technologies for Heritage Buildings Conservation: Editorial. Appl. Sci. 2021, 11, 10597. https://doi.org/10.3390/app112210597

Received: 23 July 2021

Accepted: 9 November 2021

Published: 11 November 2021

Publisher's Note: MDPI stays neutral with regard to jurisdictional claims in published maps and institutional affiliations.

Copyright: (c) 2021 by the authors. Licensee MDPI, Basel, Switzerland. This article is an open access article distributed under the terms and conditions of the Creative Commons Attribution (CC BY) license (https:/ / creativecommons.org/licenses/by/ $4.0 /)$.
Conservation of heritage buildings deserves special attention, because these buildings are not only a distinctive feature of the wisdom and creativity of the ancients, conveying abundant historic and technical information, but often they are also the symbol of a culture and represent the local community as a whole.

The concept of taking care of heritage was already present in Roman culture, two thousand years ago, as envisaged by a Cicerone sentence: Dis immortalibus, qui me non accipere modo haec a maioribus voluerunt, sed etiam posteris prodere (To the Immortal Gods, who not only wanted me to receive this from my ancestors, but also that I leave it to posterityM.T. Cicerone, 106-43 B.C., Cato Maior-De Senectute, VIII/25). Today, this principle is still applicable to cultural heritage buildings because they are the tangible heredity of our culture, history, and roots and to leave them to posterity is now on our charge.

In the XVIII century, the protection and conservation of monuments was introduced by personalities such as Williams Morris and John Ruskin and, in Italy, Luca Beltrami and Camillo Boito. During the Congress of Italian engineers and architects, held in Rome in 1883 , some principles were enunciated that should have ensured the preservation of the monuments and their correct interpretation.

In the XIX century, the theoretical formulations of the principles of restoration took place at international conferences that produced summary documents called "Restoration Charts" (Table 1).

Table 1. Restoration charters.

\begin{tabular}{c}
\hline Restoration Charters \\
\hline Athens Charter, 1931 \\
Italian Charter for Restoration, 1932 \\
Venice Charter, 1964 \\
Italian Charter for Restoration, 1972 \\
Amsterdam Charter, 1975 \\
Washington Charter, 1987 \\
Nara Document of Authenticity, 1994 \\
Krakow Charter, 2000 \\
ISO 13822-2010, 2010
\end{tabular}

The concept of anastylosis was introduced in Greek in 1836 at the Acropolis in Athens. The anastylosis, which means "to erect a stela or building again", provided a basic rule for restoration of ruined buildings or monuments of keeping the original position of the monument as well as the original architectural elements.

The Anastylosis was applied by Greek architect Nikolas Balanos to restore a collapsed portion of the Pantheon in 1902. The method was spread over to Indonesia to restore Borobudur temple by the Dutch in 1907 and to Cambodia for Angkor Monuments by a French EFEO in 1930, through a Dutch conservator. 
The Athens Charter in 1931 was adapted at the First International Congress of Architects and Technicians of Historical Monuments and may be recognized as to provide the concept of conservation of heritage monuments and structures and its importance. The charter approved the use of all the resources at the disposal of modern technique and, more especially, the use of reinforced concrete, which indicates the charter preferred the restoration of the structure over keeping the original authenticity.

The Venice Charter was adapted at the 2nd International Congress of Architects and Technicians of Historic Monuments, Venice, in 1964. The Charter was further accepted by ICOMOS in 1965. The Venice Charter followed the basic objectives of the Athens Charter but established the basic principle of authenticity of the heritage for conservation.

As inferred by Anastylosis, not only the position of the heritage structure but also various original characteristics of the heritage structure are considered for preservation. The original, as well as special characteristics of the structure, are called the defining elements of the authenticity of the structure.

The UNESCO General Assembly adopted a Convention concerning the protection of the World Culture and Natural Heritage in 1972. The Convention came into effect in 1975. The number of States Parties had reached 194 as of July 2020. Japan became a party to the Convention in 1992.

The standardization of the conservation of cultural heritage started in Europe, mainly for stone masonry structures. In other regions, such as Japan in Asia, there exists ancient temples of wooden structures that were constructed more than 1000 years ago and are treated by different methods for their conservation.

In 1996, the experts of ICOMOS gathered in Nara and discussed how to apply the principles of the conservation to other regions and published the Nara Document of Authenticity.

The Nara Document of Authenticity recognizes the various materials and structures of heritage structures that have been preserved by different methods developed by each region.

The Nara Document of Authenticity further states that the diversity of culture and heritage in our world is an irreplaceable source of spiritual and intellectual richness for all mankind.

At present, despite these charts, there is a lack of shared international compulsory rules, except the principles of authenticity-each country has its own rules for conservation of cultural heritage and guidelines for the evaluation and reduction of seismic risk for cultural heritage buildings, to be followed in conservation works.

The authenticity of the heritage structure to be preserved must be studied on forms and design, materials and substance, use and function, traditions and techniques, location and setting, and other internal and external factors.

ISO 13822: Bases for design of structures-assessment of existing structures was discussed to include the heritage structure in 2005 for 5 years. In 2010, the international standard of the restoration of heritage structure was added to the ISO 13822-2010 as Annex I Heritage Structure.

The Annex I Heritage Structure refers conservation of the authenticity of foundations as follows: From the point of view of conservation, foundations are not different from the rest of the structure and should be assessed and rehabilitated, taking into consideration their heritage value. This involves the requirement to identify their authenticity and character-defining elements.

The foundation parts of underground surfaces have been historically neglected in the conservation of heritage structures. The restoration work for the leaning Pisa Tower is one of the good examples to learn from in relation to the authenticity and foundations.

The last restoration work of the Pisa Tower was successfully completed, and it reopened to the public in December 2001 after being closed in 1990.

Several methods, such as soil extraction, grouting, and pile foundation may be available to stop or to decrease the rate of leaning (Figure 1). Among these methods, soil 
extraction was selected after a few trials of different approaches, without any discussion of the authenticity of the foundation.

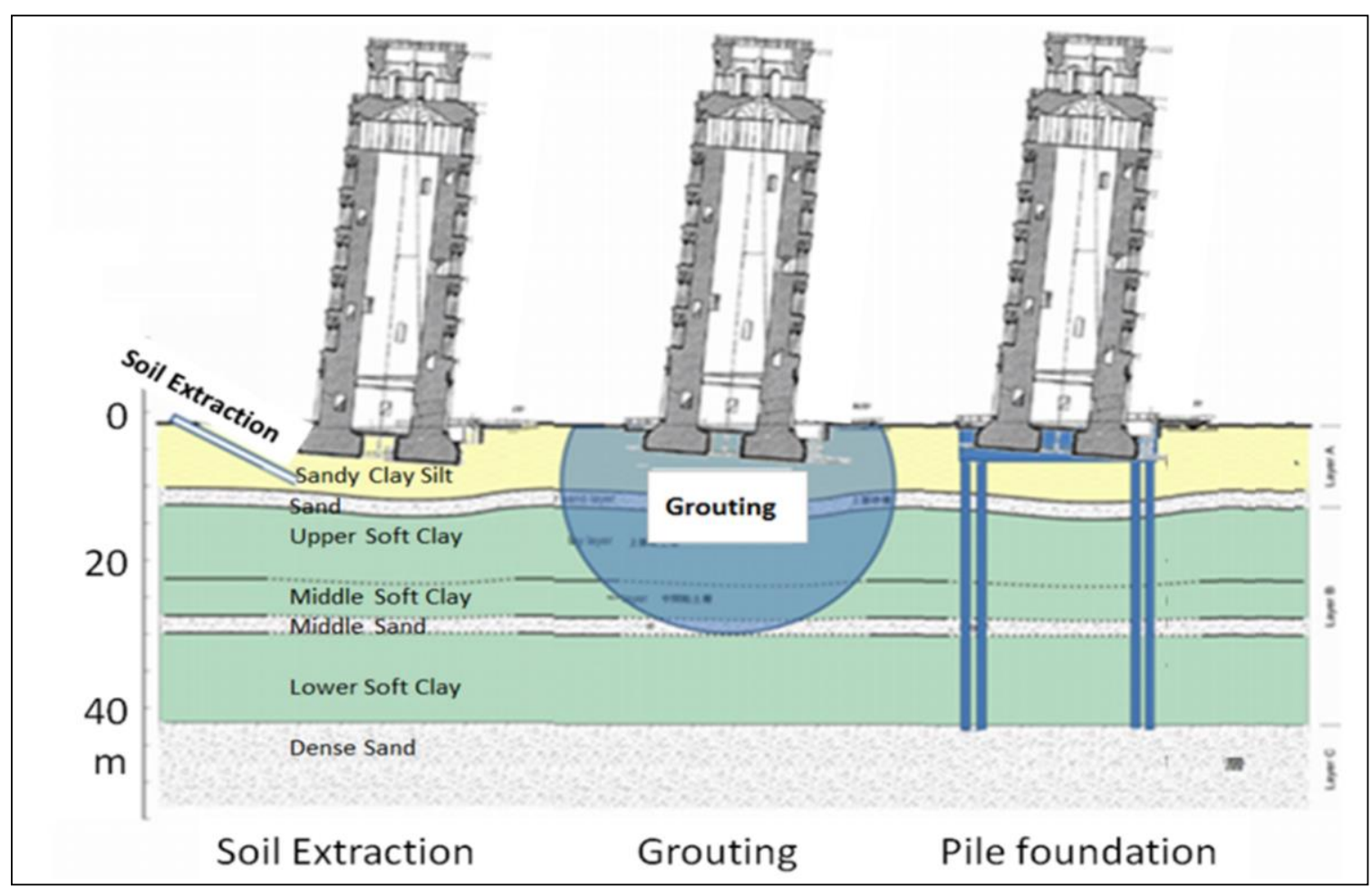

Figure 1. Restoration methods for the leaning Pisa Tower.

The main cause of the tower's incline was the direct shallow foundation on the soft ground with thick, soft clay layers. The character-defining elements of the authenticity of the foundation are identified as follows:

1. Soft clay layers of the site ground.

2. Shallow direct foundation.

If the base soil had been grouted, or the long pile foundation had been introduced, the above-mentioned characters of the authenticity of the foundation would have been completely lost. The integrity of the foundation of the Pisa Tower were to be referred to as being lost. The reality was that the soil extraction was selected after trials of some other methods. Adapting the soil extraction method resulted in keeping the character-defining elements of the authenticity, which resulted in keeping the integrity of the foundation system without any modification. It was very rare case of successful restoration of the foundation system without any discussion of the authenticity.

The authenticity of the heritage structure should be discussed before evaluation and before selecting any countermeasures for the restoration.

Conservation of heritage buildings has strong constraints when devising remedial measures and intervention techniques, because the "Integrity" and the "Authenticity" of the building must be preserved, and "Vulnerability" must be reduced. When considering the vulnerability of built heritage, it is important distinguish between the "Intrinsic Vulnerability" and the "Induced Vulnerability".

Intrinsic vulnerability is linked to the conception of the building, the used materials (stone, earth, and wood), construction techniques, and all changes or modification that took place during the long span life; additionally, a foundations assessment is crucial. Intrinsic vulnerability does not matter for the built heritage we observe today, because we lost those constructions with intrinsic severe defects. 
All these aspects represent the historic integrity of the built heritage, as they are a material witness of knowledge of the historical period in which the monuments were built.

Induced vulnerability is linked to the reduction in time of the quality of the construction, due to the natural decay of properties of the materials constituting the masonry apparatus or to induced decay due to violent external inputs like earthquakes, wars, revolutions, spoliation, and pollution.

Authenticity implies that each piece is substituted with the same material from the same source (i.e., the same stone type from the same quarry), worked and placed according to the original, traditional methods. When we identify the character-defining elements of the authenticity of material, structure, and foundation, we could compare possible countermeasures, based upon the different effects to the authenticity.

Maintenance means a continuous work for controlling the integrity of the building and, when needed, restoration interventions for its conservation, according to the authenticity principle.

We can work for avoiding or reducing induced vulnerability through conservation, the essence of which is to remove any cause of added vulnerability, in order to elongate the life of the building. Conservation includes many items, as follows:

- $\quad$ Protection from decay.

- $\quad$ Restoration of damages: structural and aesthetic.

- $\quad$ Recovering, restyling, and integration.

- $\quad$ Lasting of the functional use.

- Maintenance with same materials and techniques.

Scientific, technical, and historical knowledge are fundamental in order to recover traditional and original craft knowledge and operative techniques; today, numerical informative contents, both 2D and 3D (GIS, HBIM), are available for achieving and handing down this knowledge.

The most important act for conservation is the monitoring that guides one to daily ordinary maintenance plus spotting extraordinary interventions in the event of their necessity.

Maintenance occurs through restoration works for conserving the integrity of the building, according to the authenticity principle.

This virtuous chain demands a constant flux of economic resources. In ancient times, incomes from temples or religious complexes' real estates and properties were used for supporting and maintaining them, or they were under the patronage of a public or private institution that took care of its maintenance.

This, and the persistence of use for compatible functions, ensured the conservation of heritage buildings - the lack of this leads to decadence, ruin, and the need for extensive and expensive conservation interventions.

Summarizing, we can say that the conservation of a cultural heritage building is ensured through coherent, coordinated, and planned studies, prevention, maintenance, and restoration activities, where:

- Prevention includes all the set of activities suitable for limiting the occurrence of situations of risks related to the cultural good in its context.

- Maintenance implies all the set of activities and interventions intended for controlling the conditions of the cultural property and maintaining integrity and efficiency functional and identity of the asset and its parts.

- $\quad$ Restoration means the direct intervention on the good through a complex of operations aimed at material integrity and the recovery of the same asset, to the protection and transmission of its cultural values: for real estates located in areas at seismic risk, restoration can include structural improvement interventions.

The road map for a typical conservation of a cultural heritage buildings implies a chain of well-addressed actions (Figure 2). 


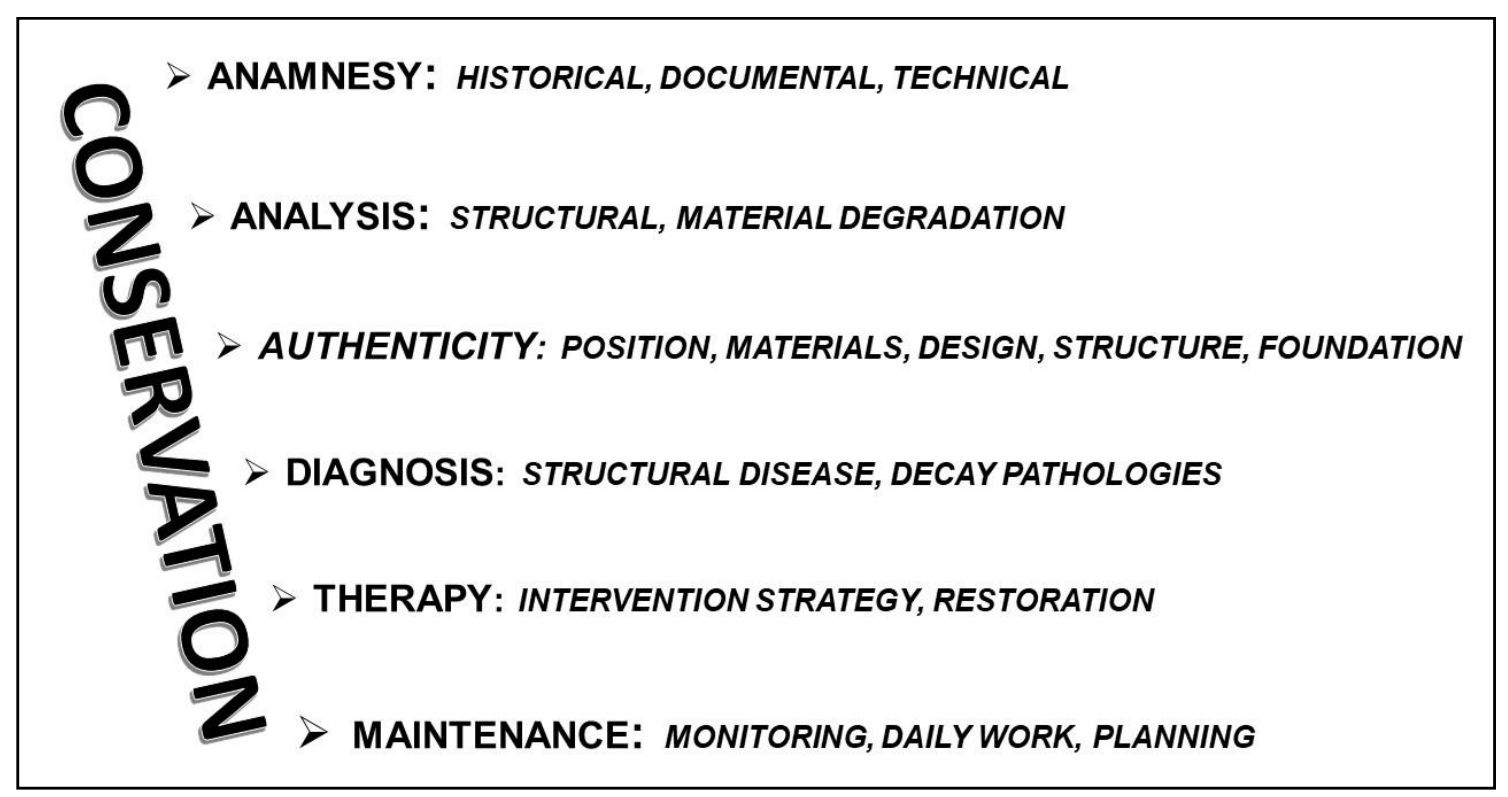

Figure 2. Virtuous chain for a typical conservation of cultural heritage buildings.

Usually, the design or documents regarding heritage buildings are not available or existing; therefore, the only mode we have for defining the masonry apparatus and structure is through non-destructive investigation techniques (NDT) of the indirect type (photogrammetry, laser scan, thermography, georadar, sonic or ultrasonic tomography, Schmidt hammer, and seismic survey) or weakly destructive direct inspections (DAC Test, endoscopies, de-scaling of plasters, essays, small trenches, and flat-jack).

This Special Issue collects five selected contributes that covers several aspects, regarding Novel Approaches and Technologies for Heritage Buildings Conservation.

The technologies addressed in the Special Issue regards the following:

- The problem of rising moisture sits in conjunction with the concept of sustainability, a problem in need of revision from a global point of view. (Application of Anti-Moisture Technologies in Historical Constructions from the Perspective of Sustainability, by Patrik Št'astný, Jozef Gašparík, Oto Makýš, Barbara Chamulová, and Sylvia Szalayová).

- The application of a 3D LIDAR technology to the arches and vaults of a Renaissance factory in the Colegio of Santo Domingo de Orihuela (16th Century) for verifying the execution process of the works and studying the different charge states. (Advances in the Restoration of Buildings with LIDAR Technology and 3D Reconstruction: Forged and Vaults of the Refectory of Santo Domingo de Orihuela (16th Century), by Pascual Saura-Gómez, Yolanda Spairani-Berrio, Jose Antonio Huesca-Tortosa, Silvia SpairaniBerrio, and Carlos Rizo-Maestre).

- The rigorously accurate representation of old construction, reachable by implementation of Historic Building Information Modelling (HBIM) a content of 4D information (3D spatial and 1D technical), which is increasingly used for historical buildings. (Generation of an HBIM Library regarding a Palace of the 19th Century in Lisbon, by Alcínia Zita Sampaio, António Mendes Pinto, Augusto Martins Gomes, and Alberto Sanchez-Lite).

- The development of diagnosis strategies for the conservation and maintenance of historic earthen walls, which is a complex theme that requires a multiple approach, as stated by as ICOFORT (International committee on fortifications and military heritage). (Multi-Criteria Parametric Verifications for Stability Diagnosis of Rammed-Earth Historic Urban Ramparts Working as Retaining Walls, by Âlvaro R. Serrano-Chacón, Emilio J. Mascort-Albea, Jacinto Canivell, Rocío Romero-Hernández, and Antonio Jaramillo-Morilla). 
- The problems connected to the conservation of an historical cladding apparatus, such as that of the Saint John Baptistery in Florence (Italy), which has been a subject in the last years of multi-disciplinary research. (Saint John Baptistery in Florence (Italy): Studies for Conservation of the External Marble Cladding, by Massimo Coli, Anna Livia Ciuffreda, Tessa Donigaglia, Attilio Bencaster, Samuele Caciagli, Beatrice Agostini, and Niccolò Iandelli).

In our opinion, the contributes cover a wide range of novel approaches and technologies for the conservation of heritage buildings, such that this Special Issue can represent a compendium for further research in the conservation of heritage buildings.

Author Contributions: M.C. and Y.I. contribute to the paper in the same menner. All authors have read and agreed to the published version of the manuscript.

Funding: This research received no external funding.

Institutional Review Board Statement: Not applicable.

Informed Consent Statement: Not applicable.

Data Availability Statement: Not applicable.

Conflicts of Interest: No any conflict of interest for both the authors. 